\title{
Semblanza de Bernabé Navarro
}

\author{
Mauricio Beuchot
}

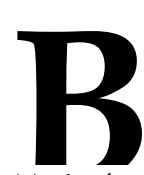

ernabé Navarro Barajas, profesor de esta facultad, murió el 8 de diciembre de 1995. Había nacido en Zapotiltic, Jalisco, el 19 de mayo de 1923; pero casi de inmediato fue llevado a Santiago Tangamandapio, Michoacán, por lo que él se consideraba michoacano. Todavía niño hubo de pasar a la capital de la República. En ella realizó la secundaria y la preparatoria humanística en el Seminario Conciliar de México, de 1936 a 1940. Allí mismo hizo estudios de filosofía escolástica, de 1940 a 1942. Desde entonces tuvo preocupación por la teoría del conocimiento, gracias a las clases de uno de sus profesores, el P. Hermilo Camacho.

Por esta época tuvo también como profesor al eminente humanista Gabriel Méndez Plancarte, quien le transmitió el gusto por las humanidades clásicas y por el pensamiento novohispano. Navarro entró en 1943 como becario en El Colegio de México (en ese entonces Casa de España en México) bajo la dirección de José Gaos, con el cual continuó su dedicación a la filosofía colonial, dentro del proyecto de Gaos de realizar la historia del pensamiento mexicano. Esta colaboración durará hasta 1947.

En 1944, Navarro ingresa a la Facultad de Filosofía y Letras de la UNAM, donde fue completando su preparación y madurando sus estudios de teoría del conocimiento con la obra de Nicolai Hartmann y con los Diálogos de Platón. También asistía a unos cursos especiales que, con un pequeño grupo, hacía con el profesor Joaquín Xirau, padre de Ramón Xirau, en la casa de éste. Esas lecciones de Xirau duraron poco tiempo, ya que el profesor español transterrado murió en un inesperado accidente, frente al edificio de Mascarones, donde estaba la Facultad, en abril de 1946. Igualmente por este tiempo Navarro encontró la guía de otro maestro transterrado, aunque también por breve tiempo, a saber, Juan David García Bacca, que le ayudó a profundizar su utilización de la filología en la filosofía, pero que dejó México a finales de ese mismo año de 1946 o a principios de 1947 (había llegado en 1942). Asimismo, reanudó sus trabajos 
con José Gaos, por un tiempo más duradero. Ya había trabajado con él en El Colegio de México, y ahora bajo su dirección realizaba la tesis de maestría, acerca de la recepción de la filosofía moderna en la Nueva España del siglo XVIII. Navarro presentó su tesis en 1947; y, como participaba como becario en el grupo que Gaos tenía en El Colegio de México laborando en el pensamiento mexicano, al año siguiente se publicó como libro en esa institución.

En 1948 Navarro es admitido en la Facultad de Filosofía y Letras de la UNAM, para impartir un curso sobre filosofía virreinal. En 1950 fue admitido como profesor de carrera. (Ya había enseñado en la Escuela Nacional Preparatoria y en otras preparatorias incorporadas, de 1946 a 1949.) Fue profesor de carrera en la facultad de 1950 a 1959. En años sabáticos y en otras ocasiones, prestó sus servicios en algunas universidades de provincia, como en la de San Luis Potosí (1955) y en el Instituto Tecnológico del Noroeste, Ciudad Obregón (1958). De 1959 a 1963 estudió en Alemania, profundizando en el problema del conocimiento, ahora con el estudio del idealismo alemán.

En la Universidad de Munich tuvo como profesor principal a Reinhardt Lauth. Entonces pudo leer directamente en la lengua de Kant sobre todo la Crítica de la razón pura, así como los continuadores del filósofo de Königsberg, en especial Fichte, sobre el que escribió su disertación doctoral. Navarro regresó a México en 1963, reincorporándose a la UNAM, y volvió a Alemania en 1966, para presentar su tesis de doctorado.

Además de haber sido profesor de carrera en la facultad, Navarro fue miembro del Centro de Estudios Filosóficos, ahora Instituto de Investigaciones Filosóficas, desde 1965. Pero continuó enseñando en la facultad, ahora en las clases del posgrado. Tuvo un seminario sobre filosofía y cultura novohispanas. En esas actividades le sorprendió la muerte en México, D. F., el 8 de diciembre de 1995.

Las áreas de su trabajo se reparten en la filosofía griega, la filosofía colonial, la filosofía del idealismo alemán y la filosofía en México. Heredó la cátedra de Filosofía en México, que había sido de Samuel Ramos. De hecho, editó y aumentó la Historia de la filosofía en México, de ese maestro (México: Conaculta, 1994).

Su labor en filosofía griega se centró en Platón y Aristóteles. Sobre Platón publicó ensayos relativos a su teoría del conocimiento, a saber, la teoría de las ideas, en la revista Diánoia, de 1972 a 1974. Acerca de Aristóteles estudió su concepción de la metafísica, y aun continuó una traducción de la Metafísica del Estagirita que José Gaos había iniciado. Pero sobre todo hay que mencionar la traducción del Aristóteles de Ingemar Düring, que se publicó en la UNAM, en 1987.

En cuanto a la filosofía colonial, en la que fue pionero, estudió sobre todo a fray Alonso de la Veracruz, a Sigüenza y Góngora, y, de manera preponderante, la modernización en el siglo XVIII. En el caso de Fray Alonso, ha estudiado sobre 
todo su Física, acerca de la cual ha publicado varios artículos. Del siglo XVII, ha dedicado su atención a Sigüenza y Góngora, cuya Libra astronómica y filosófi$c a$ ha editado, con prólogo de José Gaos (UNAM, 1959; 2a. ed. 1984). Sobre el siglo XVIII escribió La introducción de la filosofía moderna en México. México, El Colegio de México, 1948. Asimismo, reunió varios artículos publicados anteriormente en un volumen intitulado Cultura mexicana moderna en el siglo XVIII. México, UNAM, 1964 (2a. ed. 1983). Igualmente, tradujo del latín varias biografías de Juan Luis Maneiro y de Manuel Fabri en un tomo intitulado Vidas de mexicanos ilustres del siglo XVIII. México, UNAM, 1956 (2a. ed. 1989); así como un primer volumen de la obra de Juan Benito Díaz de Gamarra y Dávalos, los Elementos de filosofía moderna. México, UnAM, 1963 (2a. ed. 1984). Ha realizado la traducción de una gran parte de la Physica Particularis de Clavijero, con el título Francisco Xavier Clavijero, introductor de la filosofía moderna en Valladolid de Michoacán, hoy Morelia (Universidad Michoacana, 1995).

Por lo que hace al idealismo alemán, está su tesis sobre Fichte, publicada como libro, El desarrollo fichteano del idealismo trascendental de Kant. MéxiCO, UNAM/FCE, 1965 (Colección Diánoia); "Breve estudio de lo trascendental" (Diánoia, 1969); "Reflexiones sobre la aporía realismo-idealismo" (Diánoia, 1971). En todos sus trabajos se ve el cuidado y el primor que ponía en traducciones y análisis. Fue un profesor e investigador benemérito que legó una gran riqueza a nuestra cultura patria.

Como valoración del pensamiento de Navarro, se podría decir que su convicción acerca de ese problema que tanto lo acució, el gnoseológico, es que la esencia del conocimiento se funda en la explicación conjunta de Platón y de Kant. Por lo demás, entendió siempre la filosofía como un ejercicio riguroso y estricto de la razón sobre problemas brotados de la realidad y del hombre en el plano de los grandes principios, sobre todo en el campo de la teoría del conocimiento y de la metafísica. Se basa en los filósofos clásicos griegos, pero su labor no se queda en la de historiador de la filosofía, sino que hace filosofía en sentido propio, buscando realizar elaboración de los problemas en el campo sistemático, aunque utilizando la historia filosófica. Los autores le sirven de inspiración, pero lo que le parece la labor exacta del filósofo es trasladar lo que ellos dijeron al contexto del momento actual, para revitalizar el pensamiento filosófico del momento. Esto fue lo que intentó hacer como profesor e investigador de la UNAM. 